This is the submitted version of the article:

Jennings D., Ricote S., Santiso J ., Reimanis I.. The formation of oriented barium carbonate from the decomposition of

yttria-doped barium zirconate films. Scripta Materialia, (2020).

186. : 401 - . 10.1016/j.scriptamat.2020.05.028.

Available at:

https://dx.doi.org/10.1016/j.scriptamat.2020.05.028 


\section{The Formation of Oriented Barium Carbonate from the Decomposition of Yttria-Doped Barium Zirconate Films}

Jennings, $\mathrm{D}^{1}$; Ricote, $\mathrm{S}^{1}$; Santiso, $\mathrm{J}^{2}$; Reimanis, $\mathrm{I}^{1}$.

1. Colorado School of Mines, Golden CO, USA

2. Catalan Institute of Nanoscience and Nanotechnology, ICN2, CSIC and the Barcelona Institute of Nanoscience and Technology (BIST), Campus UAB, 08193 Bellaterra, Barcelona, Spain

Yttria-doped barium zirconate (BZY) is a perovskite ceramic of interest in various energy applications due to its high proton conductivity. BZY and similar perovskites are effective in fuel

cell and catalysis applications, and are often doped with transition metals, such as $\mathrm{Ni}[1-6]$, which act as sintering aids. Transition metal doping in BZY and similar materials also enhances catalytic performance when catalytic nanostructures are produced through exsolution[7-10]. BZY/Ni thin films show promise for studying fundamental processes in BZY, and there may be applications where thin films are preferred. Up to this point, BZY thin films have been investigated largely because of their lack of blocking grain boundaries, which has been shown to improve proton conductivity in some cases[11-18]. Proton conduction in BZY thin films has been well studied, but understanding the stability and microstructural evolution of these films in corrosive environments has so far been neglected. Understanding how the microstructure of thin films evolves in environments relevant to material performance is critical to the device applicability of BZY thin films.

In this work, we report on the decomposition of BZY/Ni thin films under conditions where decomposition is rarely seen in bulk BZY samples. Decomposition at elevated 
temperatures in $\mathrm{CO}_{2}$ containing atmospheres has been studied extensively in bulk BZY, BCY (yttria-doped barium cerate), and other proton conducting perovskites, as it is of great concern for device performance[2,19-21]. Decomposition of these perovskites in $\mathrm{CO}_{2}$ containing environments is typically characterized by the formation of $\mathrm{BaCO}_{3}$ (barium carbonate) on the surface of the material. $\mathrm{BCY}$ is highly unstable in $\mathrm{CO}_{2}$ containing environments, decomposing to $\mathrm{BaCO}_{3}$ and $\mathrm{CeO}_{2}$ (ceria). $\mathrm{BZY}$ is much more stable in $\mathrm{CO}_{2}$ containing atmospheres than $\mathrm{BCY}$, although the substitution of $\mathrm{Zr}$ in place of Ce results in a loss of protonic conductivity[2,6,10,21,22]. While bulk BZY is relatively stable, its decomposition via the formation of $\mathrm{BaCO}_{3}$ under certain conditions has been observed[23-27]. The stability of BZY thin films may differ from that of bulk BZY. It is known that epitaxially induced strain influences thin film morphological instability[28,29]. Fundamental understanding of the conditions and the mechanisms that result in BZY thin film decomposition enables the design of more stable and resilient materials.

The materials utilized in this work are $\mathrm{BZY} / \mathrm{Ni}\left(\mathrm{BaZr}_{0.85} \mathrm{Y}_{0.15} \mathrm{O}_{3-\delta}\right.$ doped with 1 wt. \% of $\mathrm{NiO}$ ) epitaxial thin films grown on (100) cut $\mathrm{SrTiO}_{3}$ (strontium titanate) single crystals. The films were grown with a Compex Pro $201 \mathrm{KrF}$ excimer laser $(\lambda=248 \mathrm{~nm})$ with the following conditions: $1 \mathrm{~Hz}$ pulse repetition rate, laser fluence of $1.7 \mathrm{~J} / \mathrm{cm}^{2}$, deposition temperature of 700 ${ }^{\circ} \mathrm{C}, \mathrm{pO}_{2}$ of $100 \mathrm{mTorr}$, and target to sample distance of $57 \mathrm{~mm}$. The target was prepared by solidstate reactive sintering, as described by Ricote, et al[30]. The optimal growth parameters for BZY deposition have been determined in previous work [17]. Thin films were grown epitaxially to the $\mathrm{SrTiO}_{3}$ substrate leading to a cube-on-cube orientation relationship between the substrate and film. The film thickness $(45 \mathrm{~nm})$ and crystallinity were confirmed with high resolution transmission electron microscopy (HRTEM) and x-ray diffraction (XRD) prior to heat 
treatments. Previous work shows that films produced by this method do not exhibit intrinsic stresses [17]. Heat treatments were performed in a dedicated gas flow tube furnace with an inserted thermocouple to measure temperature [31]. Heating was performed in three different environments: pure (99.999\%) Ar, industrial grade (99.875\%) Ar, and pure (99.0\%) $\mathrm{CO}_{2}$. All treatments were done using cut pieces of the same thin film; these thin film samples were held with microscopy wax for cutting, then cleaned in a heated ultrasonic bath with acetone and isopropanol. Transmission electron microscopy (TEM) imaging, scanning TEM (STEM) imaging, and energy dispersive spectroscopy (EDS) mapping were done with a FEI Talos F200x TEM. Scanning electron microscopy (SEM) imaging was performed with a JEOL 7000F FESEM, and time of flight secondary ion mass spectrometry (TOF-SIMS) mapping was executed using an IONTOF TOF.SIMS 5. TEM specimens were prepared by focused ion beam (FIB) milling utilizing a FEI Helios Nanolab 600i FIB.

Consistent with previous work on these films [17], all BZY films were found to be epitaxial with the STO single crystal support, as confirmed by x-ray diffraction and HRTEM imaging that showed atomic resolution arrangement across the interface. Samples heated to 800 ${ }^{\circ} \mathrm{C}$ in industrial grade (99.985\% purity) Ar for $20 \mathrm{~h}$ resulted in decomposition of the BZY film (Figure 1) as discussed in detail below. In contrast, heat treatments at $800{ }^{\circ} \mathrm{C}$ in high purity $\mathrm{Ar}$ (99.999\% purity) for $20 \mathrm{~h}$ resulted in no observable microstructural or morphological changes.

The treatment in industrial Ar, led to the formation of crystallographically oriented grains, referred to here as 'rods', on the sample surface (Figure 1). STEM and EDS were used to establish that the rods are barium carbonate (Figure 2); TOF-SIMS (presented in supplementary materials) supports this conclusion. The regions of film between the rods (Figure 1b) display features consistent with the break-up of the underlying film, and these regions were determined 
by STEM/EDS to be $\mathrm{ZrO}_{2}$ (zirconium oxide) (Figure 2). EDS mapping shows that these particles consist of $\mathrm{Y}, \mathrm{Zr}$, and $\mathrm{O}$ (with $\mathrm{Y}$ and $\mathrm{Zr}$ detected only in these particles and nowhere else). Selected area electron diffraction and high resolution imaging were attempted, but due to the small particle size, the results were inconclusive. It is additionally noted that, as discussed below, the $\mathrm{BZY}$ decomposition reaction (equation 1) to $\mathrm{BaCO}_{3}$ results in the formation of YSZ. This information, along with the composition of the starting BZY, leads to the conclusion that these particles are YSZ; YSZ15 fits correctly with the stoichiometry of the decomposition reaction. There was no clear orientation relationship between the YSZ crystals and the STO substrate.

The decomposition of BZY into $\mathrm{BaCO}_{3}$ and $\mathrm{YSZ}$ is consistent with previous observations in bulk $\mathrm{BaZrO}_{3} / \mathrm{BaCeO}_{3}$ type materials in the presence of $\mathrm{CO}_{2}$ [23-27]. As discussed below, it is hypothesized that $\mathrm{CO}_{2}$ is formed from $\mathrm{O}_{2}$ present in industrial grade $\mathrm{Ar}$ and $\mathrm{C}$ present during sample preparation. Decomposition was not uniform across the entire sample; in one corner of the sample shown in Figure 1, a section of film that had not decomposed was observed (Figure 1c). The result of this was a transition region between the intact and decomposed sections of the BZY thin film that gives insight to the process of decomposition. A higher magnification view of the transition region between the decomposed and un-decomposed film (Figure 1d) reveals small ( $100 \mathrm{~nm}$ across) $\mathrm{BaCO}_{3}$ crystallites. It appears that the formation of $\mathrm{BaCO}_{3}$ precedes or occurs simultaneously with the disappearance of BZY.

In the presence of $\mathrm{CO}_{2}$ the decomposition reaction may be described by the following (removing Ni for simplicity and using the symbol $\delta$ to denote the oxygen stoichiometry):

$$
\mathrm{BaZr}_{0.85} \mathrm{Y}_{0.15} \mathrm{O}_{3-\delta}+\mathrm{CO}_{2} \rightarrow \mathrm{BaCO}_{3}+\mathrm{Zr}_{0.85} \mathrm{Y}_{0.15} \mathrm{O}_{2-\delta}
$$


According to Eqn (1), $\mathrm{BaCO}_{3}$ and YSZ form simultaneously. Eqn (1) suggests that $\mathrm{Y}$ should be in solid solution with Zr, consistent with the EDS map (Figure 2) that places Y wherever there is $\mathrm{Zr}$ (note that $\mathrm{Zr}$ and $\mathrm{Y}$ signal is also detected in the protective Pt layer, a result of fluorescence and peak overlap). Ni was detected by EDS in the YSZ crystals, but not in the $\mathrm{BaCO}_{3}$ material, indicating that some Ni remains in solution in the YSZ after decomposition (supplementary materials). Ni has similar solubility in both YSZ and BZY[32-36], so it is somewhat expected that $\mathrm{Ni}$ would remain with the YSZ phase during decomposition. As there is no driving force for $\mathrm{Ni}$ exsolution in this heat treatment, the Ni remains in solution despite the decomposition of the BZY phase. The process of film decomposition can be deduced by examining different sections of the sample near the transition region (Figure 1c, d). It is proposed that the first step in this process is $\mathrm{BaCO}_{3}$ nucleation on the $\mathrm{BZY}$ surface. Figure 1d exhibits small $\mathrm{BaCO}_{3}$ crystallites that may be nuclei. There is no indication of $\mathrm{C}$ at the BZY/STO interface, but it is expected that there would be residual $\mathrm{C}$ from the sample preparation and cleaning process. Therefore, $\mathrm{BaCO}_{3}$, which needs $\mathrm{C}$ to form, would nucleates on the surface of the BZY film rather than at the interface with $\mathrm{SrTiO}_{3}$.

Cross sectional HRTEM (Figure $2 \mathrm{~b}$ and supplemental material) revealed there is a $4 \mathrm{~nm}$ thick amorphous layer at the interface between the $\mathrm{BaCO}_{3}$ rods and the $\mathrm{SrTiO}_{3}$ substrate, demonstrating that $\mathrm{BaCO}_{3}$ does not grow epitaxially on the $\mathrm{SrTiO}_{3}$, despite the fact that it displays an orientation relationship with $\mathrm{SrTiO}_{3}$. This observation supports the hypothesis that $\mathrm{BaCO}_{3}$ nucleates on the surface of the BZY and establishes its crystallographic orientation from BZY. Once $\mathrm{BaCO}_{3}$ grains have nucleated, they grow in size, removing barium from the BZY film, resulting in decomposition of the film. The $\mathrm{BaCO}_{3}$ rods are aligned parallel to the (110) planes of the initial epitaxial BZY film, which indicates this is a low energy orientation 
relationship between those two phases. The shape of the $\mathrm{BaCO}_{3}$ rods is dictated by the surface energy of the various crystal facets. TEM (Figure 2) indicates that the rods grow to surround the YSZ particles, and extend about $100 \mathrm{~nm}$ past the original BZY surface. Electron diffraction was utilized to determine the crystal structure of the $\mathrm{BaCO}_{3}$ crystals. It was found that the $\mathrm{BaCO}_{3}$ crystals in this study have a slightly different space group and large lattice distortions when compared to bulk witherite which is the typical crystalline structure of $\mathrm{BaCO}_{3}$. Witherite has lattice parameters of $\mathrm{a}=5.3 \AA, \mathrm{b}=8.9 \AA$, and $\mathrm{c}=6.4 \AA[37]$ whereas in the present case, the crystals were found to be a distorted witherite structure, with the lattice parameters of $a=5.5 \AA$, $\mathrm{b}=9.5 \AA$, and $\mathrm{c}=8.5 \AA$. Future studies will investigate the cause of these structural distortions. Electron diffraction patterns from the $\mathrm{BaCO}_{3}$ show satellite peaks (Figure 2d) that are consistent with twinning defects. Twin planes can be clearly seen in the $\mathrm{BaCO}_{3}$ crystal in the TEM image in Figure $2 b$.

It is proposed that the $\mathrm{CO}_{2}$ from the decomposition reaction (Eqn 1) originated from one of two sources: 1. C contamination of the sample from the cutting and cleaning procedures prior to heat treatment; 2. $\mathrm{CO}_{2}$ impurity in industrial grade Ar. In the former case, the presence of $\mathrm{O}_{2}$, a known impurity in industrial grade $(99.985 \%)$ Ar, would be expected to react with $\mathrm{C}$ at high temperatures to form $\mathrm{CO}_{2}$. The latter case is possible, but the industrial Ar stream was assessed for impurities with mass spectrometry (MS), and it was found that $\mathrm{CO}_{2}$ levels were near or below the detection limit of the MS ( 10ppm). Furthermore, $\mathrm{O}_{2}$ was detected in the MS measurement. It is concluded that $\mathrm{C}$ impurities arising from contamination during cutting and cleaning the samples reacted with $\mathrm{O}_{2}$ in the industrial $\mathrm{Ar}$ to form $\mathrm{CO}_{2}$. The presence of a transition region supports this conclusion, as it suggests that the $\mathrm{C}$ contamination was concentrated on one side of the thin film sample. 
It was also observed that the BZY films can experience morphological instability (Figure 3a) simultaneous with the formation of $\mathrm{BaCO}_{3}$ rods as shown for another sample heat treated in industrial grade $\operatorname{Ar}\left(800{ }^{\circ} \mathrm{C}, 20 \mathrm{~h}\right.$ ) (Figure 3a). When the films were heated to $800{ }^{\circ} \mathrm{C}$ under pure $\mathrm{CO}_{2}$ for $20 \mathrm{~h}$, the results were similar to those for the heat treatments in industrial $\mathrm{Ar}$ (Figure $3 \mathrm{~b}$ ). Namely, BZY displayed film break-up and oriented $\mathrm{BaCO}_{3}$ rods formed.

$\mathrm{BaZrO}_{3}$ is thermodynamically stable at temperatures above about $600{ }^{\circ} \mathrm{C}$ in $1 \mathrm{~atm}$ of $\mathrm{CO}_{2}$ [2]. It is unstable below this temperature, though at lower temperatures a decomposition reaction is expected to be kinetically hindered and has not been reported under these conditions. Since the peak temperature in the heat treatments of the present studies was always $800^{\circ} \mathrm{C}$, thermodynamic calculations for undoped $\mathrm{BaZrO}_{3}[2]$ imply that decomposition occurs during heating or cooling. Y doping has been reported to decrease thermodynamic stability of $\mathrm{BaZrO}_{3}[38]$ and Ni may have a similar effect, possibly changing the temperature at which decomposition occurs.

It may be the case that the morphological stability of the thin film plays a role in the decomposition kinetics of BZY. Film dewetting, a phenomenon driven by the minimization of surface and interface energies[39,40] may be an additional driving force for solid state diffusion necessary for the decomposition reaction. It is further possible that elastic strain energy minimization adds an another kinetic driving force [41], though it is expected to be small here because the as-deposited films are relaxed [17], and the thermal residual stresses upon heating are expected to be relatively small $[42,43]$. In conditions where the decomposition reaction (Eqn 1) of bulk BZY would be kinetically hindered, thin films could undergo decomposition due to the increase in solid state diffusion in thin film samples where morphological instability is occurring simultaneously. It is also possible that this type of decomposition does occur in bulk 
BZY, but goes undiscovered in bulk materials. In the present case, the decomposition is easily observed because the starting BZY film is less than $50 \mathrm{~nm}$ thick. The observations presented here imply that the decomposition in thin films of BZY is dictated by some combination of film morphological instability, a process that is enhanced at elevated temperatures $[44,45]$, and equation (1) which has a greater thermodynamic driving force at lower temperatures [2]. Future work should be directed towards understanding the combined effects of morphological instabilities and reaction (1) on thin film BZY.

The observation that $\mathrm{BaCO}_{3}$ forms into rods with crystallographic orientation aligned with the underlying STO substrate is significant because it suggests a way by which to control the formation of oxide nano- and microstructures. In this case, it is shown that the $\mathrm{BaCO}_{3}$ rods actually form on the surface of the highly epitaxial BZY thin-film, and that the rods therefore display a particular crystallographic arrangement with the substrate and each other. Moreover, these results provide insight into the conditions under which thin BZY films degrade.

This work was funded through the National Science Foundation via grant DMR1563754. Additionally, this material makes use of the TOF-SIMS system at the Colorado School of Mines, which was supported by the National Science Foundation under Grant No.1726898. The authors would like to thank Michael Walker, Dr. Michael Sanders and Dr. George Burton for their contributions to this work. JS would like to thank ICN2 for funding through the CERCA programme/Generalitat de Catalunya and by the Severo Ochoa programme (SEV-2017-0706). 
[1] H. Iwahara, H. Uchida, K. Morimoto, J. Electrochem. Soc. 137 (1990) 462-465.

[2] K.H. Ryu, S.M. Haile, Solid State Ionics 125 (1999) 355-367.

[3] Y. Yamazaki, R. Hernandez-sanchez, S.M. Haile, Chem. Mater. 21 (2009) 2755-2762.

[4] C. Duan, J. Tong, M. Shang, S. Nikodemski, M. Sanders, S. Ricote, A. Almansoori, R. O’Hayre, Science (80-. ). 349 (2015) 1321-1326.

[5] D.M. Jennings, C. Karakaya, H. Zhu, C. Duan, R. O’Hayre, G.S. Jackson, I.E. Reimanis, R.J. Kee, Catal. Letters 148 (2018) 3592-3607.

[6] M. Seo, S.Y. Kim, Y.D. Kim, E.D. Park, S. Uhm, Int. J. Hydrogen Energy 43 (2018) $11355-11362$.

[7] D. Neagu, G. Tsekouras, D.N. Miller, H. Menard, J.T.S. Irvine, Nat. Chem. 5 (2013) 916923.

[8] D. Neagu, T. Oh, D.N. Miller, H. Menard, S.M. Bukhari, S.R. Gamble, R.J. Gorte, J.M. Vohs, J.T.S. Irvine, Nat. Commun. 6 (2015) 1-8.

[9] N. Nasani, D. Pukazhselvan, A. V. Kovalevsky, A.L. Shaula, D.P. Fagg, J. Power Sources 339 (2017) 93-102.

[10] C. Duan, R.J. Kee, H. Zhu, C. Karakaya, Y. Chen, S. Ricote, A. Jarry, E.J. Crumlin, D. Hook, R. Braun, N.P. Sullivan, R. O’Hayre, Nature 557 (2018) 217-222.

[11] J.H. Shim, T.M. Gür, F.B. Prinz, Appl. Phys. Lett 92 (2008) 2531151-2531153.

[12] J. Hyung Shim, J. Sun Park, J. An, T.M. G, S. Kang, F.B. Prinz, Chem. Mater 21 (2009) 3290-3296.

[13] D. Pergolesi, E. Fabbri, A. D’Epifanio, E. Di Bartolomeo, A. Tebano, S. Sanna, S. Licoccia, G. Balestrino, E. Traversa, Nat. Mater. 9 (2010) 846-852.

[14] Y.B. Kim, T.M. Gür, H.J. Jung, S. Kang, R. Sinclair, F.B. Prinz, Solid State Ionics 198 
(2011) 39-46.

[15] N. Yang, C. Cantoni, V. Foglietti, A. Tebano, A. Belianinov, E. Strelcov, S. Jesse, D. Di Castro, E. Di Bartolomeo, S. Licoccia, S. V. Kalinin, G. Balestrino, C. Aruta, Nano Lett. 15 (2015) 2343-2349.

[16] Z. Liu, F. Zarotti, Y. Shi, N. Yang, J. Phys. Chem. C 123 (2019) 20698-20704.

[17] A. Magrasó, B. Ballesteros, R. Rodríguez-lamas, M.F. Sunding, J. Santiso, Solid State Ionics 314 (2018) 9-16.

[18] A. Jarry, S. Ricote, A. Geller, C. Pellegrinelli, X. Zhang, D. Stewart, I. Takeuchi, E. Wachsman, E.J. Crumlin, B. Eichhorn, ACS Appl. Mater. Interfaces (2018) 37661-37670.

[19] S. Gopalan, A. V Virkar, J. Electrochem. Soc. 140 (1993) 1060-1065.

[20] K.D. Kreuer, Solid State Ionics 125 (1999) 285-302.

[21] K. Katahira, Y. Kohchi, T. Shimura, H. Iwahara, Solid State Ionics 138 (2000) 91-98.

[22] S. Wienströer, H.D. Wiemhöfer, Solid State Ionics 101-103 (1997) 1113-1117.

[23] C.S. Tu, R.R. Chien, V.H. Schmidt, S.C. Lee, C.C. Huang, C.L. Tsai, J. Appl. Phys. 105 (2009) 1035041-1035047.

[24] N. Yan, Y. Zeng, B. Shalchi, W. Wang, T. Gao, G. Rothenberg, J. Luo, J. Electrochem. Soc. 162 (2015) 1408-1414.

[25] T. Ishiyama, H. Kishimoto, K. Develos-Bagarinao, K. Yamaji, T. Yamaguchi, Y. Fujishiro, J. Ceram. Soc. Japan 125 (2017) 247-251.

[26] R. Sazinas, M.F. Sunding, A. Thogersen, I. Sakaguchi, T. Norby, T. Grande, J.M. Polfus, J. Mater. Chem. A 7 (2019) 3848-3856.

[27] R. Sazinas, C. Bernuy-Lopez, M.-A. Einarsrud, T. Grande, J. Am. Ceram. Soc. 99 (2016) 3685-3695. 
[28] M. Coll, J. Gázquez, A. Pomar, T. Puig, F. Sandiumenge, X. Obradors, Phys. Rev. B 73 (2006) 0754201-0754208.

[29] F. Cheynis, E. Bussmann, F. Leroy, T. Passanante, P. Müller, Int. J. Nanotechnol. (2012) $397-411$.

[30] S. Ricote, N. Bonanos, A. Manerbino, W.G. Coors, Int. J. Hydrogen Energy 37 (2012) 7954-7961.

[31] A. Morrissey, The Reduction of Nickel Doped Fluorite and Perovskite Structured Oxides, 2015.

[32] A. Kuzjukevics, S. Linderoth, Solid State Ionics 93 (1997) 255-261.

[33] G. Dhalenne, B. Bonvalot, A. Revcolevschi, F. Millot, J. Am. Ceram. Soc. 73 (1990) $1524-1528$.

[34] S. Chen, W. Deng, P. Shen, Mater. Sci. Eng. 22 (1994) 247-255.

[35] S. Ricote, N. Bonanos, Solid State Ionics 181 (2010) 694-700.

[36] J.M. Polfus, M. Fontaine, A. Thøgersen, M. Riktor, T. Norby, R. Bredesen, J. Mater. Chem. A 4 (2016) 8105-8112.

[37] J.P.R. De Villiers, Am. Minerol. 56 (1971) 758-767.

[38] M.D. Gonçalves, P.S. Maram, R. Muccillo, A. Navrotsky, J. Mater. Chem. A 2 (2014) $17840-17847$.

[39] D.J. Srolovitz, Acta Metall. 37 (1989) 621-625.

[40] C. V. Thompson, Annu. Rev. Mater. Res. 42 (2012) 399-434.

[41] W.D. Kaplan, D. Chatain, P. Wynblatt, W.C. Carter, J. Mater. Sci. 48 (2013) 5681-5717.

[42] Y. Zhao, D.J. Weidner, Phys. Chem. Miner. 18 (1991) 294-301.

[43] D. de Ligny, P. Richet, Phys. Rev. B 53 (1996) 3013-3022. 
[44] Y. Ono, M. Nagase, M. Tabe, Y. Takahashi, Jpn. J. Appl. Phys. 34 (1995) 1728-1735.

[45] V.G. Lifshits, I.G. Kaverina, V. V Korobtsov, A.A. Saranin, A. V Zotov, Thin Solid Films 135 (1986) 99-105. 
Figure Captions

Figure 1: SEM image of a sample heat treated in industrial grade $\mathrm{Ar}(99.985 \%)$ at $800{ }^{\circ} \mathrm{C}$ for 20 h. (a) Highly oriented $\mathrm{BaCO}_{3}$ crystallites on the STO substrate. (b) A higher magnification image reveals YSZ particles in between the $\mathrm{BaCO}_{3}$ crystallites. (c) A 'transition' region of the film that displays decomposition (upper left) and no decomposition (lower right) and (d) In a higher magnification image of the transition region there appear to be $\mathrm{BaCO}_{3}$ nuclei present in the unbroken film (bright spots in the bottom right quadrant of the micrograph).

Figure 2: (a) STEM/EDS elemental mapping, showing a cross section of a $\mathrm{BaCO}_{3}$ crystal. YSZ particles and the $\mathrm{SrTiO}_{3}$ substrate are visible. It can clearly be seen that the $\mathrm{BaCO}_{3}$ crystals have grown over the YSZ particles. (b) TEM bright field image of another $\mathrm{BaCO}_{3}$ crystal. (c,d) Selected area diffraction patterns of two orientations of the $\mathrm{BaCO}_{3}$ crystal detail structure variations, including satellite spots resulting from twinning defects in the crystal.

Figure 3: (a) SEM of a film that experienced morphological instability after a heat treatment with industrial $\mathrm{Ar}\left(800^{\circ} \mathrm{C}, 20 \mathrm{~h}\right) \mathrm{BaCO}_{3}$ rods are visible. (b) SEM of film decomposition after a heat treatment in a $\mathrm{CO}_{2}$ environment $\left(800{ }^{\circ} \mathrm{C}, 20 \mathrm{~h}\right)$. 
Figure 1
Click here to download high resolution image

Figure 1
Click here to download high resolution image

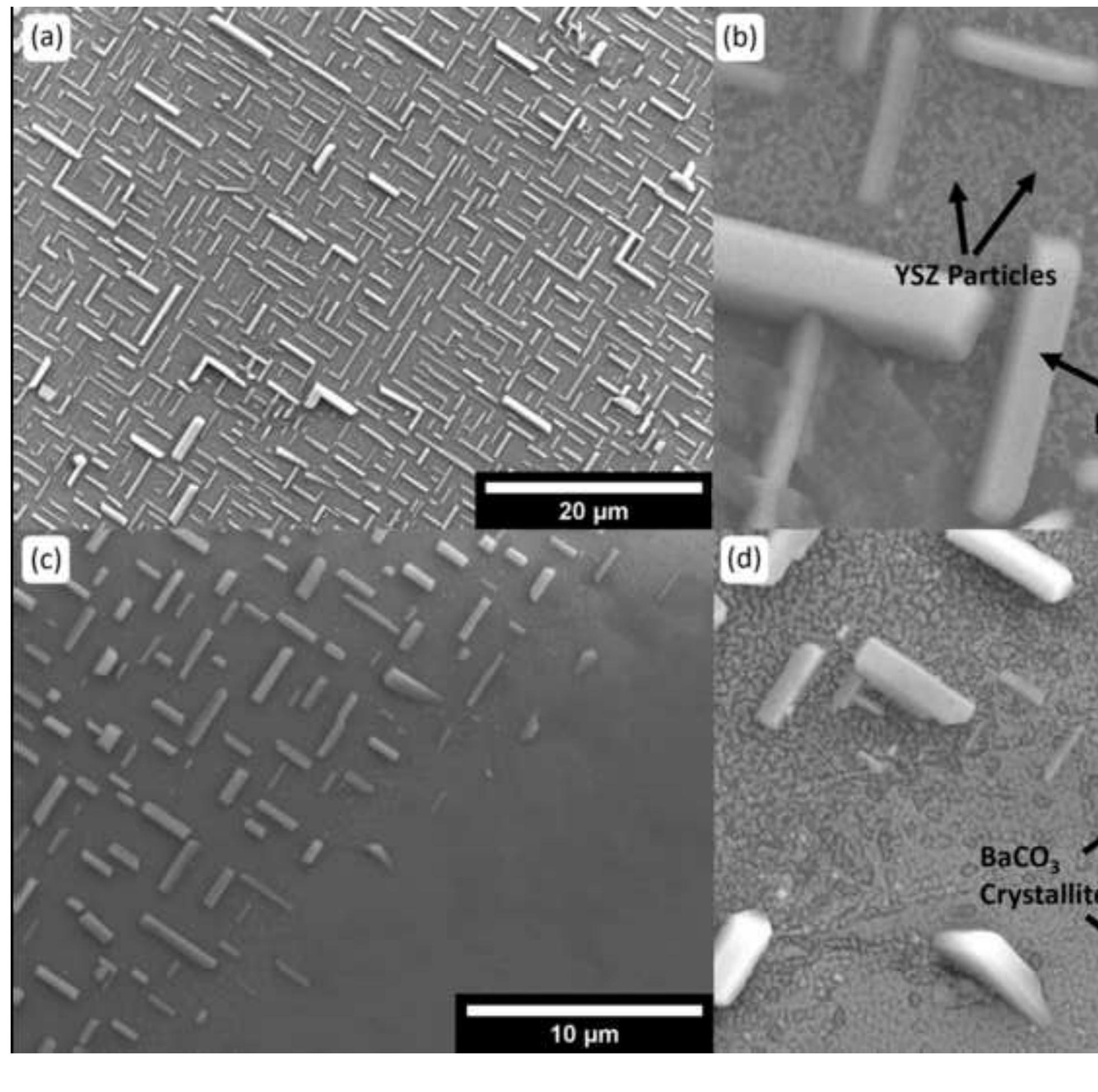

(b) 
Figure 2

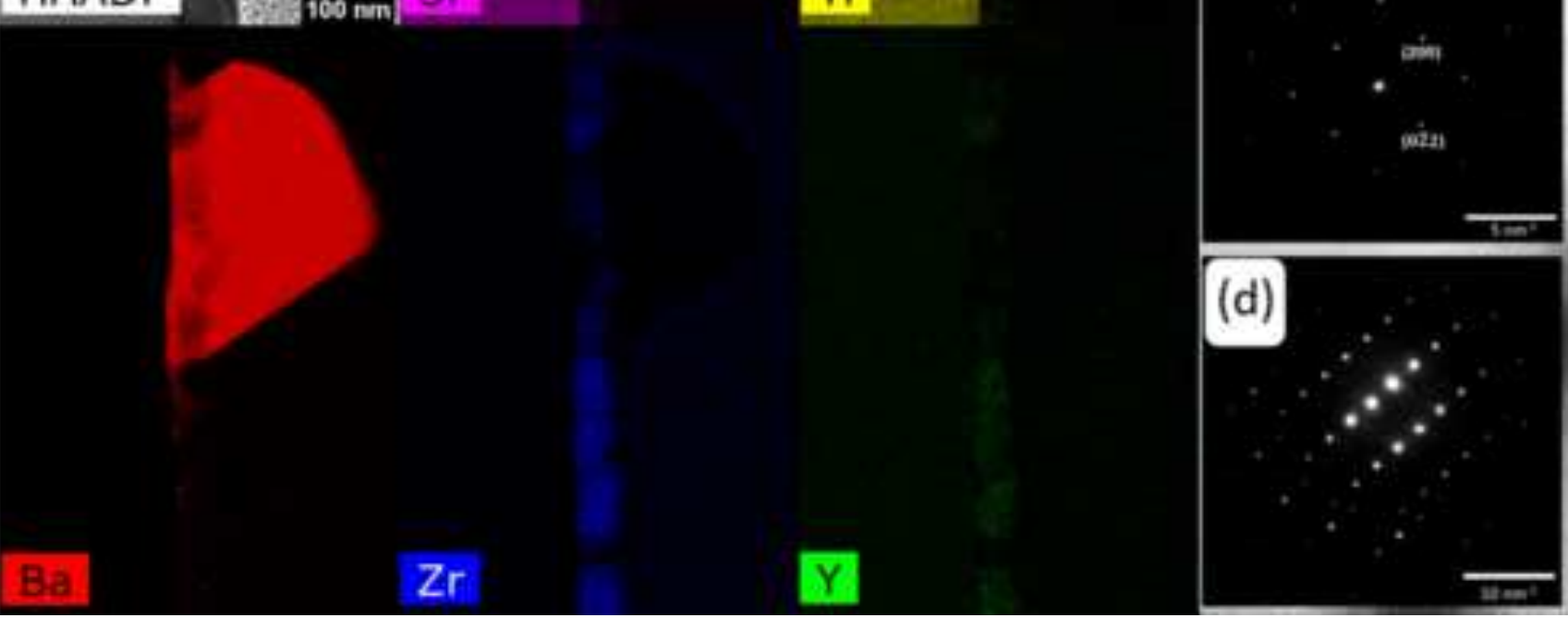

Click here to download high resolution image

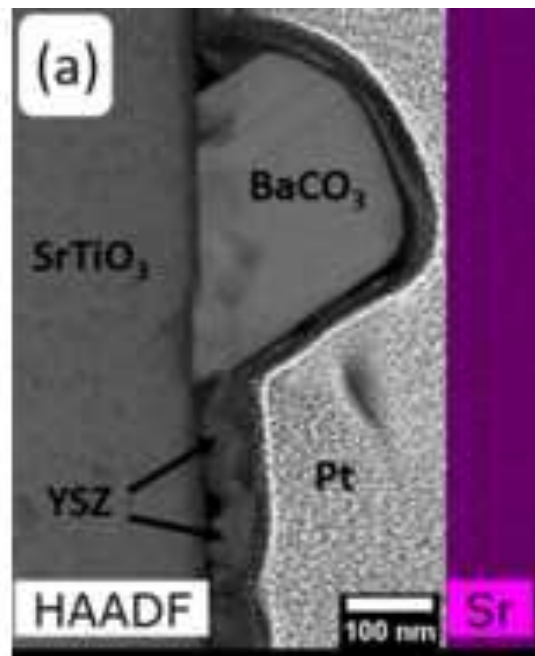

\section{(b)}

\section{(c)}
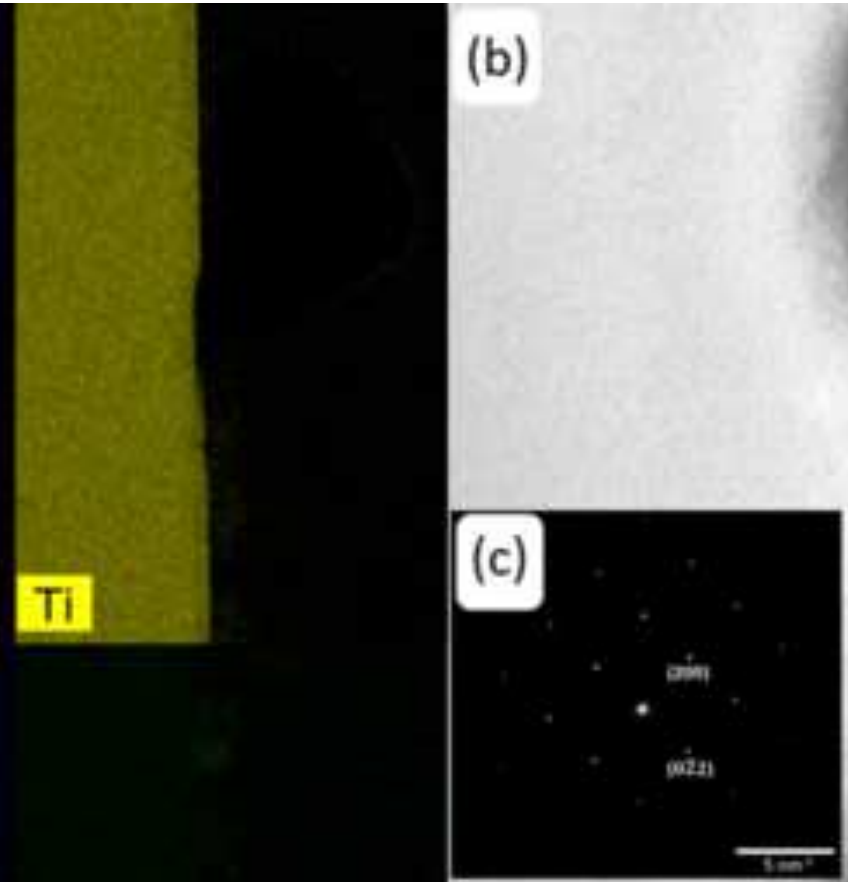

(d)

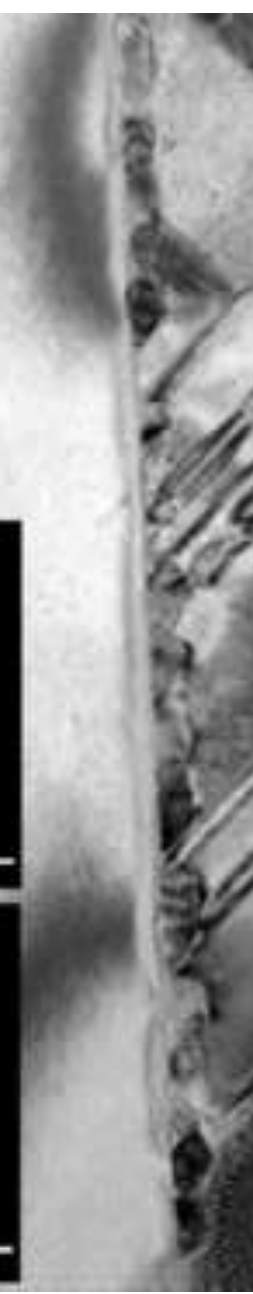


Figure 3
Click here to download high resolution image

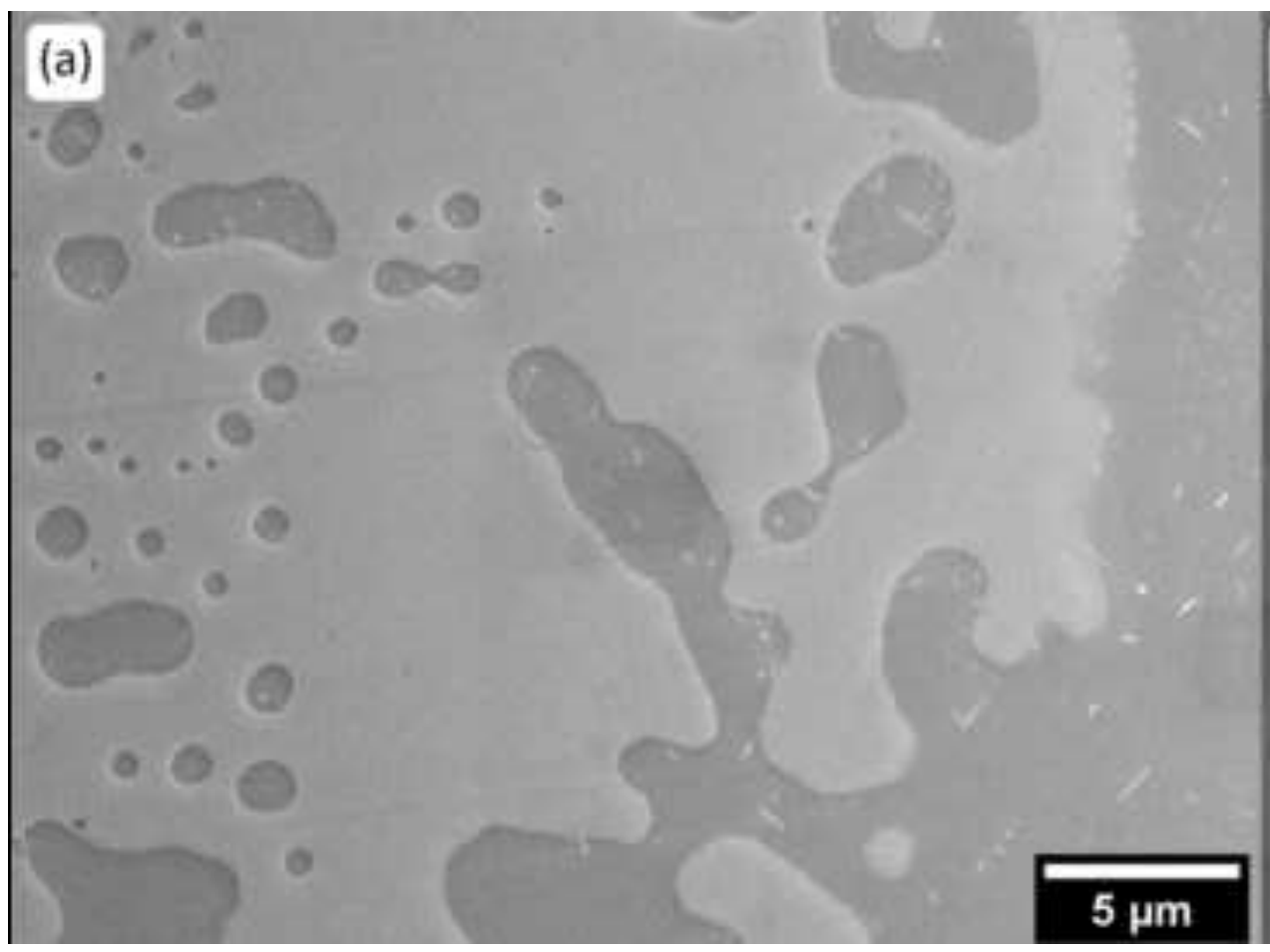

(b) 
Supplementary Information:
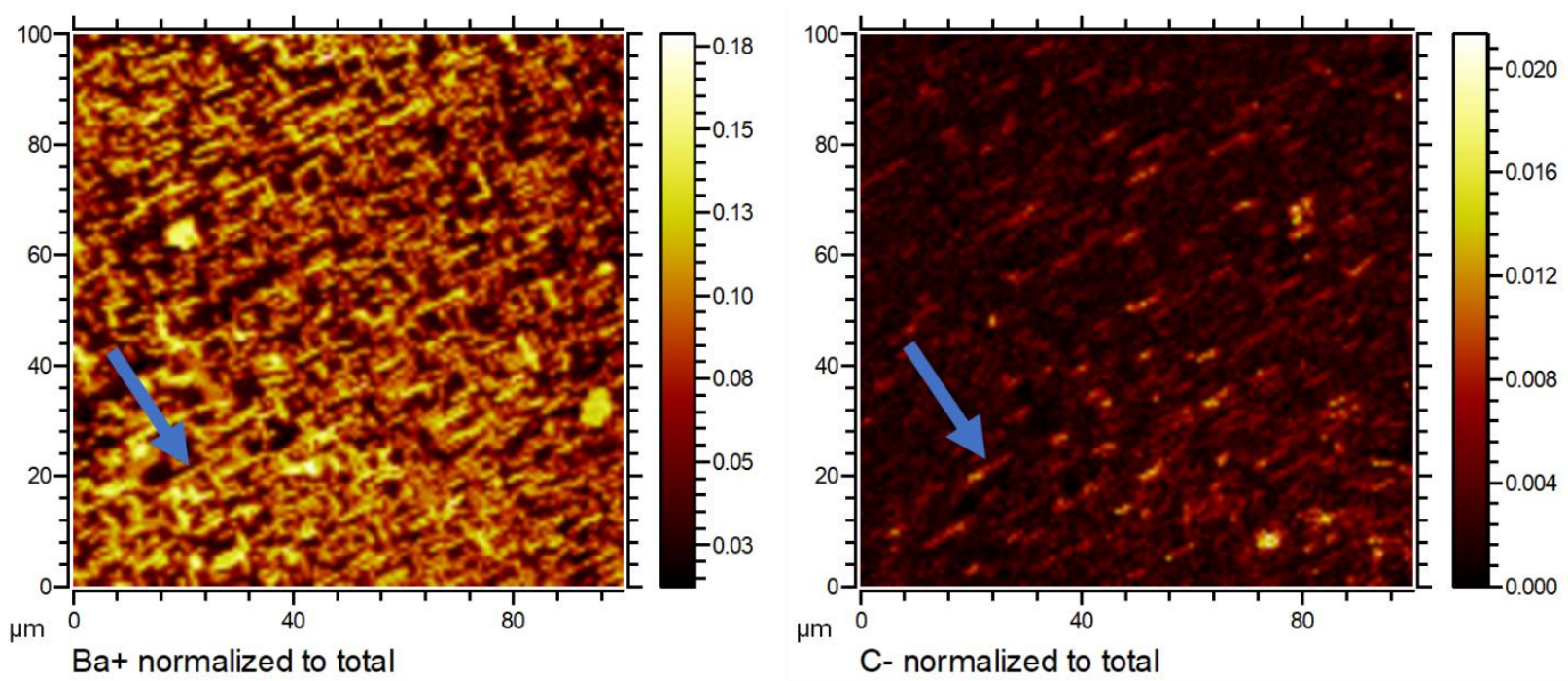

Figure S1: $\mathrm{Ba}$ and $\mathrm{C}$ spatial mapping produced utilizing TOF-SIMS. $\mathrm{BaCO}_{3}$ crystals can be seen in both the $\mathrm{Ba}$ and $\mathrm{C}$ maps, with one crystal pointed out in each map.

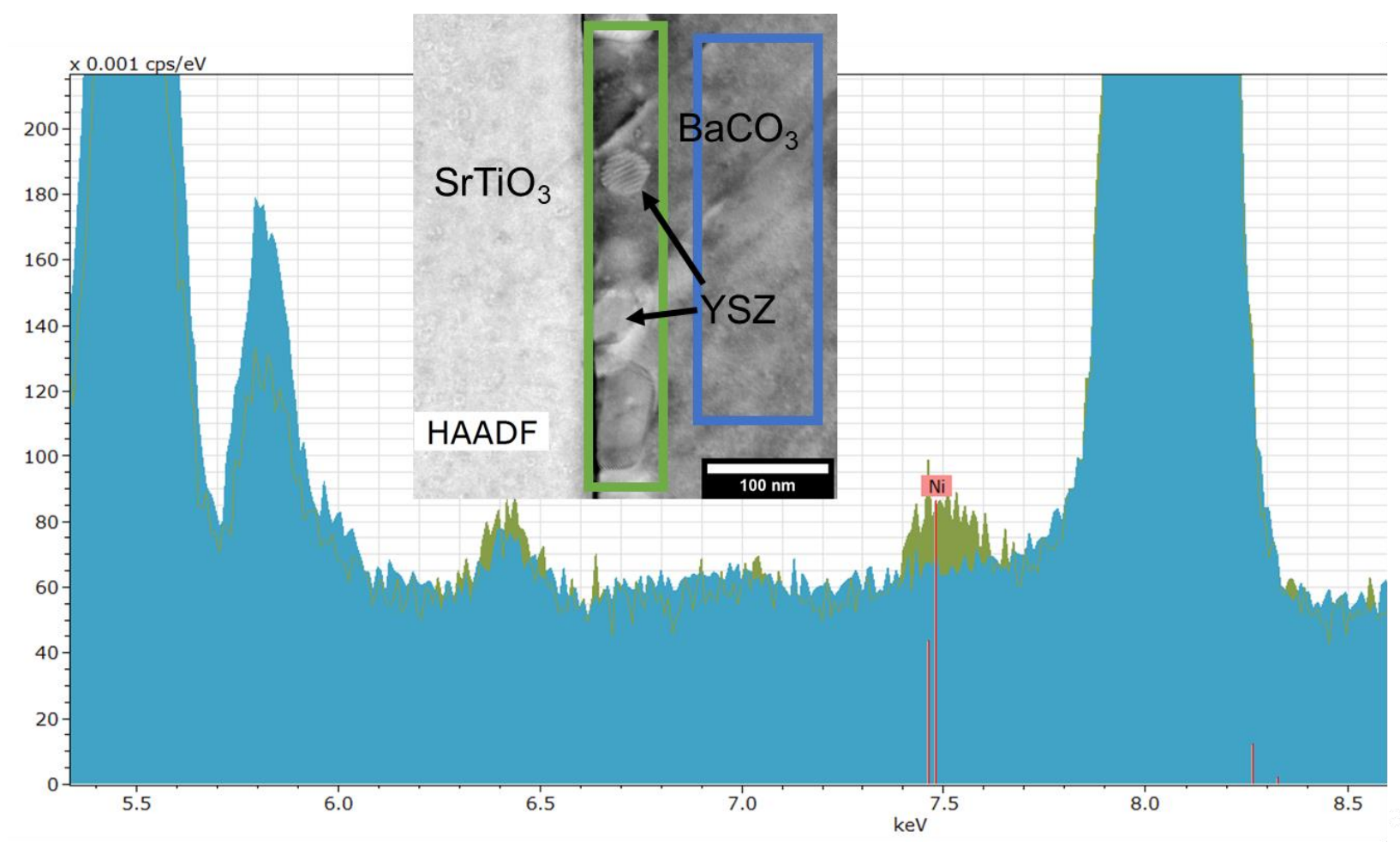

Figure S2: Selected area from an EDS spectra showing, in blue, signal coming solely from a $\mathrm{BaCO}_{3}$ crystal, and in green, an area including the YSZ grains. The Ni signal is only visible in the area with YSZ, indicating that $\mathrm{Ni}$ is in solution in the YSZ after decomposition. 


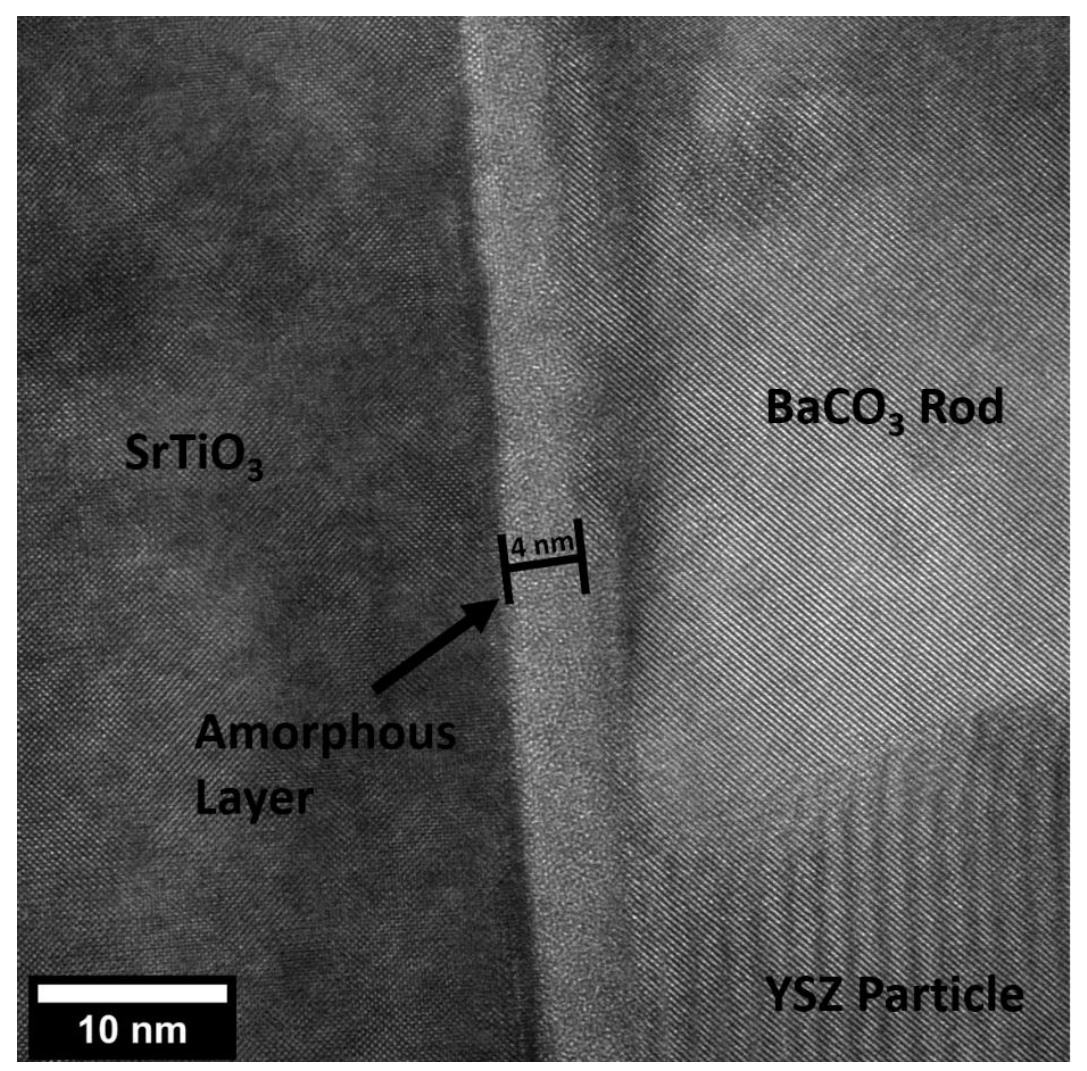

Figure S3: HRTEM image detailing the presence of an amorphous area between the $\mathrm{BaCO}_{3}$ rod and the $\mathrm{SrTiO}_{3}$ support. This supports the hypothesis that the $\mathrm{BaCO}_{3}$ nucleates on the surface of the initial BZY film. Additionally, a YSZ particle can be seen within the $\mathrm{BaCO}_{3}$ rod, as indicated by the moiré pattern present in the image. 